\title{
Lack of evidence for a genetic association between FGF20 and Parkinson's disease in Finnish and Greek patients
} Jordi Clarimon*1, Georgia Xiromerisiou ${ }^{1,2}$, Johanna Eerola ${ }^{3}$, Vanesa Gourbali², Olli Hellström ${ }^{4}$, Euthimios Dardiotis ${ }^{2}$, Terhi Peuralinna ${ }^{3}$, Alexandros Papadimitriou ${ }^{2}$, George M Hadjigeorgiou ${ }^{2}$, Pentti J Tienari ${ }^{3}$ and Andrew B Singleton ${ }^{1}$

\author{
Address: ${ }^{1}$ Molecular Genetics Unit, Laboratory of Neurogenetics. National Institute on Aging, National Institutes of Health, Building 35 Room \\ 1A1000. Bethesda, MD 20892 USA, ${ }^{2}$ Neurogenetics Unit, Department of Neurology, Medical School, University of Thessaly, Larissa, Greece, \\ ${ }^{3}$ Department of Neurology, Helsinki University Central Hospital and University of Helsinki Biomedicum-Helsinki, Neuroscience Programme, \\ Finland and ${ }^{4}$ Department of Neurology, Seinäjoki Central Hospital, Finland \\ Email: Jordi Clarimon* - clarimon@mail.nih.gov; Georgia Xiromerisiou - xiromerisiouge@mail.nih.gov; \\ Johanna Eerola - Johanna.eerola@helsinki.fi; Vanesa Gourbali - geocl83x@hotmail.com; Olli Hellström - olli.hellstrom@epshp.fi; \\ Euthimios Dardiotis - edar@med.uth.gr; Terhi Peuralinna - terhi.peuralinna@helsinki.fi; \\ Alexandros Papadimitriou - alexpapadimitriou@yahoo.com; George M Hadjigeorgiou - gmhadji@yahoo.com; \\ Pentti J Tienari - pentti.tienari@hus.fi; Andrew B Singleton - singleta@mail.nih.gov \\ * Corresponding author
}

Published: 20 June 2005

BMC Neurology 2005, 5:II doi:10.1 186//47|-2377-5-II
Received: 06 April 2005

Accepted: 20 June 2005

This article is available from: http://www.biomedcentral.com/I47I-2377/5/I I

(c) 2005 Clarimon et al; licensee BioMed Central Ltd.

This is an Open Access article distributed under the terms of the Creative Commons Attribution License (http://creativecommons.org/licenses/by/2.0), which permits unrestricted use, distribution, and reproduction in any medium, provided the original work is properly cited.

\begin{abstract}
Background: Fibroblast growth factor 20 (FGF20) is a neurotrophic factor preferentially expressed in the substantia nigra of rat brain and could be involved in dopaminergic neurons survival. Recently, a strong genetic association has been found between FGF2O gene and the risk of suffering from Parkinson's disease (PD). Our aim was to replicate this association in two independent populations.
\end{abstract}

Methods: Allelic, genotypic, and haplotype frequencies of four biallelic polymorphisms were assessed in I5I sporadic PD cases and I86 controls from Greece, and I44 sporadic PD patients and 135 controls from Finland.

Results: No association was found in any of the populations studied.

Conclusion: Taken together, these findings suggest that common genetic variants in FGF20 are not a risk factor for PD in, at least, some European populations.

\section{Background}

Parkinson's disease (PD), with a prevalence of nearly $2 \%$ in those older than 65 years of age, is one of the most common neurodegenerative disorders [1]. The cause of its clinical features (bradykinesia, rigidity, resting tremor, and postural instability) is the selective degeneration of dopaminergic neurons in the substantia nigra, leading to a deficiency of dopamine in their striatal projections areas. Although the etiology of PD is still unclear, increasing evidence suggest that genetic factors are likely to contribute $[2,3]$. To date, mutations in seven genes have been related to mendelian forms of the disease, and several loci 
across the genome have also been identified to be influencing not only familial, but also sporadic forms of PD [46]. One of the extant linkages to late onset PD is on chromosome 8p [7]. Analysis of candidate genes located within the region through the use of the pedigree disequilibrium test in 644 families, demonstrated a significant association between several polymorphisms at the fibroblast growth factor 20 (FGF20) and PD [8]. FGF20 is a neurotrophic factor widely expressed in dopaminergic neurons of the substantia nigra pars compacta [9], and enhances the survival of midbrain dopaminergic neurons [10].

We have attempted to replicate the previously described association by performing a case-control analysis in two different series: one from Finland and the other from Greece.

\section{Methods}

\section{Patients and healthy individuals}

The Finnish series is composed of 144 sporadic PD patients (mean age 67.2 years, range 38 to $88,41 \%$ women) and 135 neurologically normal healthy control subjects (mean age 65.8 years, range 37 to $80,64 \%$ women). Eleven patients had an onset before 45 years old. All individuals were recruited from the Neurological outpatient clinics of the Helsinki University Central Hospital and Seinäjoki Central Hospital. Patients were diagnosed according to PD Society Brain Bank criteria [11] and were either followed for at least 4 years or, alternatively, clinical follow-up for at least 2 years plus ${ }^{123}$ I- $\beta$-CIT-SPECT findings supporting idiopathic PD. Patients with dementia or patients who reported first-degree relatives with parkinsonism were excluded. Written informed consent was obtained from all participants. The Ethical Review Committee of the Department of Neurology at the Helsinki University Central Hospital approved the study.

The Greek series is composed of 151 sporadic PD patients (mean age 70.3, range 40 to 95, 46\% women) and 186 age-, gender-and ethnicity-matched neurologically healthy controls. Three patients had an onset before 45 years old. All patients were residents of Thessaly (Central Greece) and were identified prospectively during a 3-year period (2001-2004) in the outpatient clinic for movement disorders in Larissa University Hospital and were followed up for at least one year and up to 3 years. The diagnosis of PD was based on established criteria [4].

After approval from Hospital Scientific Committee and informed consent, blood samples were drawn for DNA extraction from patients and controls.

\section{Genotyping}

Taqman $^{\circledR}$ Assays-by-Design ${ }^{S M}$ SNP Genotyping (Applied Biosystems) based assays were employed for allelic discrimination of the two intronic SNPs (rs1989756 and rs 1989754) as well as the 3'UTR SNP rs1721100. Thermal cycling and end-point PCR analysis was performed on an ABI PRISM ${ }^{\circledast} 7900 H T$ Sequence Detection System and analyzed with SDS software (Applied Biosystems). Another SNP at the 3'UTR (rs20399075), which is located 99 base pairs (bp) from rs1721100, was genotyped using a restriction fragment length polymorphism (RFLP) approach. In brief, a PCR was conducted using the following primers: forward, 5'-AGTCTATTTTCTACTGAGAG-3'; and reverse, 5'-TAAGGACTAATCCAATGTATC-3'. The 139 bp amplified product was digested with 10 units of $B s p H I$ restriction enzyme and fragments were resolved on a $2 \%$ agarose gel stained with ethidium bromide. Two fragments of 80 bp and 59 bp appeared when a PCR fragment containing a cytosine in the polymorphic site was present.

\section{Statistical analysis}

Odds ratios and Chi square tests were calculated using SPSS v11.0 software for windows. Linkage disequilibrium was assessed by means of a genotype association test, implemented in the Arlqeuin ver.2.000 program, and haplotype frequencies were estimated with an expectation-maximization (EM) algorithm, also implemented in the Arlequin ver.2.000 program [12]. Comparison of FGF20 haplotype frequencies between cases and controls was performed using Fisher's exact test. Power calculations were performed with the epidemiological program EpiInfo version 6. Pomelo Tool software http:// pomelo.bioinfo.cnio.es was used for multiple testing corrections.

\section{Results}

Distribution of genotype frequencies are presented in Table 1. All polymorphisms were in Hardy-Weinberg equilibrium for PD patients and controls in both the Greek and the Finnish series. No statistically significant differences in genotype frequency were found between cases and controls in the Greek series. Allele frequencies also showed no significant association with disease in this series (data not shown). When we focused on the Finnish individuals, a slightly but not significant overrepresentation of the GG genotype in the two intronic polymorphisms (rs1989756 and rs1989754) was identified in patients compared to controls $(P=0.087$ and 0.089 respectively). There was significant increase in the rs $1989754 \mathrm{G}$ allele in patients compared to control Finnish individuals (52\% vs. $42 \%, P=0.030)$. Comparison of the rs1989756, rs1721100, and ss20399075 allele frequencies did not reveal any significant differences $(P=$ $0.099, P=0.239$, and $P=0.424$ respectively). Repeating 
Table I: FGF20 genotype frequencies in cases and controls

\begin{tabular}{|c|c|c|c|c|}
\hline \multirow[b]{2}{*}{ rsl989756 } & \multicolumn{2}{|l|}{ Finnish series } & \multicolumn{2}{|l|}{ Greek series } \\
\hline & PD cases $(\%)$ & Controls (\%) & PD cases $(\%)$ & Controls (\%) \\
\hline GG & $130(90.3)$ & $110(83.3)$ & $124(82.1)$ & $153(83.6)$ \\
\hline GA & 14 (9.7) & $22(16.7)$ & $25(16.6)$ & $29(15.8)$ \\
\hline \multirow[t]{2}{*}{ AA } & 0 & 0 & $2(1.3)$ & I (0.5) \\
\hline & $\chi^{2}(2 d f) ; 2.928$ & $P=0.087$ & $\chi^{2}(2 \mathrm{df}) ; 0.605$ & $P=0.739$ \\
\hline \multicolumn{5}{|l|}{ rs1989754 } \\
\hline GG & $39(27.1)$ & $27(20.1)$ & $30(20.0)$ & $34(19.2)$ \\
\hline GC & 71 (49.3) & $60(44.8)$ & $63(42.0)$ & $85(48.0)$ \\
\hline \multirow[t]{2}{*}{$\mathrm{CC}$} & $34(23.6)$ & $47(35.1)$ & $57(38.0)$ & $58(32.8)$ \\
\hline & $\chi^{2}(2 \mathrm{df}) ; 4.838$ & $P=0.089$ & $\chi^{2}(2 \mathrm{df}) ; 1.309$ & $P=0.520$ \\
\hline \multicolumn{5}{|l|}{ rs 1721100} \\
\hline $\mathrm{CC}$ & $74(51.4)$ & 68 (51.9) & $73(50.3)$ & $90(50.3)$ \\
\hline CG & $60(4 I .7)$ & $48(36.6)$ & 57 (39.3) & 75 (4I.9) \\
\hline \multirow[t]{2}{*}{ GG } & $10(6.9)$ & I5 (II.5) & $15(10.3)$ & I4 (7.8) \\
\hline & $\chi^{2}(2 \mathrm{df}) ; 1.977$ & $P=0.372$ & $\chi^{2}(2 \mathrm{df}) ; 0.702$ & $P=0.704$ \\
\hline \multicolumn{5}{|l|}{ ss20399075 } \\
\hline TT & $8(6.6)$ & $4(3.3)$ & $2(1.4)$ & 0 \\
\hline $\mathrm{TC}$ & $36(29.5)$ & $36(29.5)$ & $32(21.8)$ & 39 (21.7) \\
\hline \multirow[t]{2}{*}{$\mathrm{CC}$} & 78 (63.9) & $82(67.2)$ & $113(76.9)$ & $|4|(78.3)$ \\
\hline & $\chi^{2}(2 \mathrm{df}) ; 1.433$ & $P=0.488$ & $\chi^{2}(2 \mathrm{df}) ; 2.472$ & $P=0.291$ \\
\hline
\end{tabular}

Table 2: FGF20 haplotype frequencies distributions

\begin{tabular}{|c|c|c|c|c|}
\hline & \multicolumn{2}{|c|}{ Finnish sample a } & \multicolumn{2}{|c|}{ Greek sample b } \\
\hline & PD cases & Controls & PD cases & Controls \\
\hline G G C C & $42.6 \%$ & $33.8 \%$ & $33.8 \%$ & $40.4 \%$ \\
\hline GCG C & $17.9 \%$ & $23.4 \%$ & $17.0 \%$ & $19.4 \%$ \\
\hline $\mathrm{GCCC}$ & $16.1 \%$ & $15.7 \%$ & $21.4 \%$ & $19.4 \%$ \\
\hline G G C T & $8.6 \%$ & $8.2 \%$ & $2.6 \%$ & $1.9 \%$ \\
\hline G C G T & $8.2 \%$ & $5.6 \%$ & $9.2 \%$ & $8.0 \%$ \\
\hline$A \subset C C$ & $2.4 \%$ & $8.3 \%$ & $9.6 \%$ & $8.2 \%$ \\
\hline$*$ & $4.8 \%$ & $5.0 \%$ & $6.4 \%$ & $2.7 \%$ \\
\hline
\end{tabular}

a Fisher's exact test, $P=0.113$.

b Fisher's exact test, $P=0.073$

* Other haplotypes with frequencies lower than $5 \%$.

The order of SNPs are: rs 1989756, rs 1989754, rs I72 II00, and ss20399075.

the analyses after the exclusion of all early onset cases did not result in any significant changes (data not shown).

Linkage disequilibrium (LD) analysis revealed a strong $\mathrm{LD}$ between all the neighboring markers $(P$ values $<0.01$ in all comparisons). Only the neighboring SNPs rs 1721100 and ss20399075 did not show significant LD in the Finnish control group.
No significant difference in the distribution of four marker haplotypes between cases and controls was found in either of the series (see Table 2). Just a slightly decrease of the GGCC haplotype in Greek PD patients was found compared to control individuals $(P=0.073)$. 


\section{Discussion}

Among all the comparisons that we have performed; only polymorphism rs1989754 G allele frequency was significantly higher in patients than controls in the Finnish sample. However, when we adjusted for multiple testing in order to control for a type I error by means of a permutation test, the $P$ value was not longer significant.

Taking into account the allele frequencies, our study has a power of detecting risks from 1.7 to 3.6 in the Finnish sample and from 1.6 to 2.1 in the Greek series with $80 \%$ power (95\% confidence interval). These results, thus, suggest that FGF20 is not a major risk factor for sporadic PD in the Finnish and Greek population.

The present work does not replicate the recently reported association between polymorphisms at the FGF20 gene and PD [8]. It is important to note that we have genotyped the same polymorphisms that they previously performed except the one located upstream the exon 1 (ss20399076) because this was not found in the SNP database and we could not localize this SNP based on the published report. Nevertheless, because no association was reported between this SNP and PD, the absence of this polymorphism in our work should not be a major limitation.

Several reasons could explain the discrepancy between our results and the one by Van der Walt and collaborators [8]: first, the reported positive association could be the result of a type I error, due to possible admixture. Population stratification due to ethnic admixture could have been the result of using US based sample, which was not fully detailed by the authors. Another possible explanation for the lack of replication could be the result of using different epidemiological approaches. We believe that the association reported by Walt et al. should be strong enough to be consistent when other genetic epidemiology methods are employed. Since the reported $p$ values are in the order of $1 * 10 \mathrm{E}-3$, one could expect a similar pattern of association, independently of the method utilized. Therefore, it seems very improbable that the lack of replication is due to the use of another methodology. A third interpretation could be that the association is real but the effect is smaller in Greek and Finnish individuals. If this was true, our series may not be large enough to assess variants that contribute to complex traits and are likely to have modest effects. Fourth and finally, a real association could exist only in groups of a specific ethnic origin and, presumably, a similar genetic background.

\section{Conclusion}

In order to test whether the previously described association between FGF20 and PD is consistent in other populations, we have performed a case-control study in which we compare and analyze four biallelic polymorphisms within FGF20 gene in two different populations from Europe: one from Greece and one from Finland. Our results clearly indicate that genetic variations in FGF20 do not influence the risk of PD in these two populations. As far as we know, this is the only study that has tried to replicate the previous reported association between FGF20 and PD.

\section{Competing interests}

The author(s) declare that they have no competing interests.

\section{Authors' contributions}

JC performed the genotyping, statistical analysis, and drafted the manuscript. GX, JE, VG, OH, ED, TP, AP, $\mathrm{GMH}$, and PJT, contributed to collecting materials and participated in its design and coordination together with drafting the manuscript. ABS conceived the study and participated in the conceptual design and coordination of this work, together with drafting the manuscript.

\section{Acknowledgements}

Supported in part by the Helsinki University Central Hospital, The Finnish Cultural Foundation.

\section{References}

I. de Rijk MC, Tzourio C, Breteler MM, Dartigues JF, Amaducci L, Lopez-Pousa S, Manubens-Bertran JM, Alperovitch A, Rocca WA: Prevalence of parkinsonism and Parkinson's disease in Europe: the EUROPARKINSON Collaborative Study. European Community Concerted Action on the Epidemiology of Parkinson's disease. J Neurol Neurosurg Psychiatry 1997, 62:10-15.

2. Sveinbjornsdottir S, Hicks AA, Jonsson T, Petursson H, Gugmundsson G, Frigge ML, Kong A, Gulcher JR, Stefansson K: Familial aggregation of Parkinson's disease in Iceland. N Engl J Med 2000, 343:1765-1770.

3. Payami H, Zareparsi S, James D, Nutt J: Familial aggregation of Parkinson disease: a comparative study of early-onset and late-onset disease. Arch Neurol 2002, 59:848-850.

4. Hardy J, Cookson MR, Singleton A: Genes and parkinsonism. Lancet Neurol 2003, 2:221-228.

5. Gwinn-Hardy K: Genetics of parkinsonism. Mov Disord 2002, 17:645-656.

6. Paisan-Ruiz C, Jain S, Evans EW, Gilks WP, Simon J, van der Brug M, de Munain AL, Aparicio S, Gil AM, Khan N, Johnson J, Martinez JR, Nicholl D, Carrera IM, Pena AS, de Silva R, Lees A, Marti-Masso JF, Perez-Tur J, Wood NW, Singleton AB: Cloning of the gene containing mutations that cause PARK8-linked Parkinson's disease. Neuron 2004, 44:595-600.

7. Scott WK, Nance MA, Watts RL, Hubble JP, Koller WC, Lyons K, Pahwa R, Stern MB, Colcher A, Hiner BC, Jankovic J, Ondo WG, Allen FHJ, Goetz CG, Small GW, Masterman D, Mastaglia F, Laing NG, Stajich JM, Slotterbeck B, Booze MW, Ribble RC, Rampersaud E, West SG, Gibson RA, Middleton LT, Roses AD, Haines JL, Scott BL, Vance JM, Pericak-Vance MA: Complete genomic screen in Parkinson disease: evidence for multiple genes. Jama 200I, 286:2239-2244.

8. van der Walt JM, Noureddine MA, Kittappa R, Hauser MA, Scott WK, McKay R, Zhang F, Stajich JM, Fujiwara K, Scott BL, Pericak-Vance MA, Vance JM, Martin ER: Fibroblast growth factor 20 polymorphisms and haplotypes strongly influence risk of Parkinson disease. Am J Hum Genet 2004, 74: I I I I- I 27.

9. Ohmachi S, Watanabe Y, Mikami T, Kusu N, Ibi T, Akaike A, Itoh N: FGF-20, a novel neurotrophic factor, preferentially expressed in the substantia nigra pars compacta of rat brain. Biochem Biophys Res Commun 2000, 277:355-360. 
10. Ohmachi S, Mikami T, Konishi M, Miyake A, Itoh N: Preferential neurotrophic activity of fibroblast growth factor-20 for dopaminergic neurons through fibroblast growth factor receptor-I c. J Neurosci Res 2003, 72:436-443.

II. Hughes AJ, Daniel SE, Kilford L, Lees AJ: Accuracy of clinical diagnosis of idiopathic Parkinson's disease: a clinico-pathological study of 100 cases. J Neurol Neurosurg Psychiatry 1992, 55: I8I-I84.

\section{Pre-publication history}

The pre-publication history for this paper can be accessed here:

http://www.biomedcentral.com/1471-2377/5/11/prepub

Publish with Bio Med Central and every scientist can read your work free of charge

"BioMed Central will be the most significant development for disseminating the results of biomedical research in our lifetime. " Sir Paul Nurse, Cancer Research UK

Your research papers will be:

- available free of charge to the entire biomedical community

- peer reviewed and published immediately upon acceptance

- cited in PubMed and archived on PubMed Central

- yours - you keep the copyright

Submit your manuscript here:

http://www.biomedcentral.com/info/publishing_adv.asp 